\title{
Hydrogen Assisted Fracture of 30MnB5 High Strength Steel: A Case Study
}

\author{
Garikoitz Artola ${ }^{1, *(1)}$ and Javier Aldazabal ${ }^{2}(\mathbb{D}$ \\ 1 Azterlan, Research and Development of Metallurgical Processes, Aliendalde Auzunea 6, 48200 Durango, Spain \\ 2 Tecnun, University of Navarra, Manuel de Lardizábal 15, 20018 San Sebastian, Spain; jaldazabal@tecnun.es \\ * Correspondence: gartola@azterlan.es; Tel.: +34-946-21-54-70
}

Received: 6 November 2020; Accepted: 26 November 2020; Published: 30 November 2020

check for updates

\begin{abstract}
When steel components fail in service due to the intervention of hydrogen assisted cracking, discussion of the root cause arises. The failure is frequently blamed on component design, working conditions, the manufacturing process, or the raw material. This work studies the influence of quench and tempering and hot-dip galvanizing on the hydrogen embrittlement behavior of a high strength steel. Slow strain rate tensile testing has been employed to assess this influence. Two sets of specimens have been tested, both in air and immersed in synthetic seawater, at three process steps: in the delivery condition of the raw material, after heat treatment and after heat treatment plus hot-dip galvanizing. One of the specimen sets has been tested without further manipulation and the other set has been tested after applying a hydrogen effusion treatment. The outcome, for this case study, is that fracture risk issues only arise due to hydrogen re-embrittlement in wet service.
\end{abstract}

Keywords: hydrogen re-embrittlement; environmentally assisted cracking; galvanic protection; high strength steel

\section{Introduction}

High strength steels offer multiple design and cost advantages. Their most publicized application is in automotive components, where their use is being promoted by progressively more restrictive $\mathrm{CO}_{2}$ emission control policies. Components manufactured in these steels favor a reduction in emissions and an improved gas mileage thanks to their lightweight design. Other sectors such as oil \& gas are also prone to take advantage of high strength steels, such as in jack-ups and mooring chains for offshore platforms [1]. In this case, weight reduction is relevant to optimize the cost of keeping the structures floating and moored at their intended position.

The fastener market also benefits from high strength steels in terms of cost competitiveness [2]. Employing class 10.9 instead of class 8.8 bolts not only allows a reduction in the number of elements employed in a joint thanks to the $20 \%$ higher strength of the 10.9 class; it also means a bolt diameter reduction that is accompanied by a flange size reduction and a reduced installation time. Figure 1 shows a scheme in terms of cost.

Despite the fact that high strength steels are attractive cost-wise, they suffer some drawbacks, such as their increased risk of showing Hydrogen Embrittlement (HE) issues. HE causes a deterioration of mechanical properties which is often related to corrosion processes [3,4] and HE affected components fracture under applied stresses which are well below their design specifications. Bolts are a representative example of components which are concerned by this HE susceptibility, as recognized by the existence of fastener-specific standards to account for HE control in the final product [5]. 


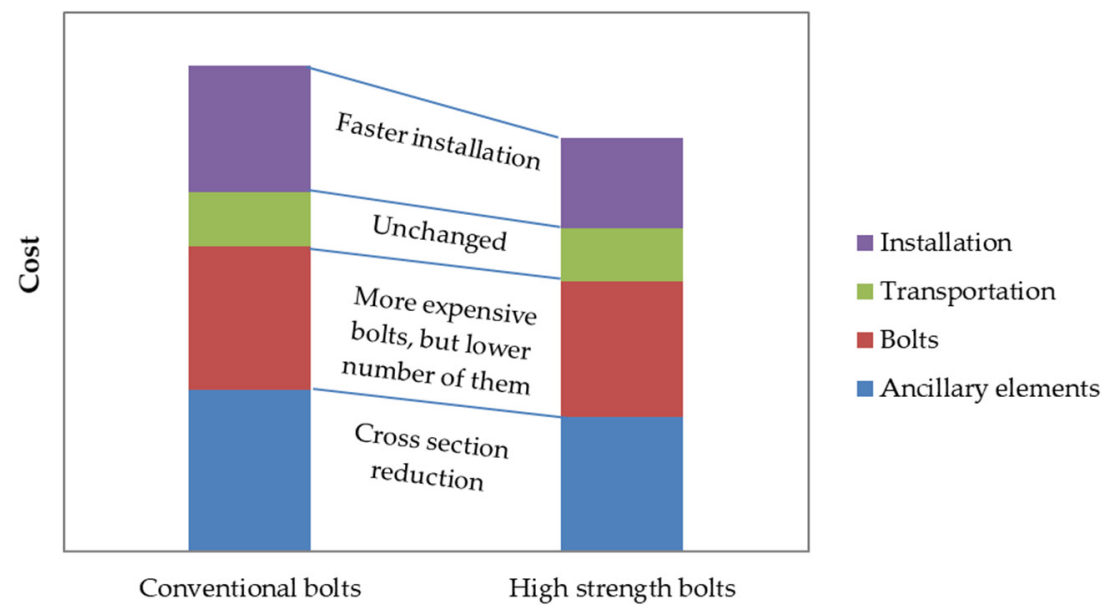

Figure 1. Scheme of the cost advantages that the use of high strength steels implies in bolted joints [2].

When the hydrogen is incorporated into the steels, during the manufacturing process of the component or during service, is referred as internal or external hydrogen, respectively [6].

Internal hydrogen can be incorporated at different steps of the manufacturing route [7], starting upstream in the molten metal [8]. Hydrogen intake is minimized at this stage by applying vacuum degassing techniques on the melt. The importance of this degassing is such that it has become compulsory in some industries [9]. In the case of cast steel parts, the hydrogen left in the melt is expelled from the metal into micro-shrinkage and gas porosity voids during solidifications. The hydrogen trapped in this way recombines into gaseous $\mathrm{H}_{2}$ in the pores and it is difficult to dissociate it again into atomic hydrogen for removal. In the case of wrought products, hot forging and/or hot rolling aid in the closing the porosity due to solidification and help the removal of hydrogen excess from the steel by the combination of deformation and temperature. The higher the rolling reduction, the lower the hydrogen content in the final material.

After casting and/or forging processes, there are two known sources of internal hydrogen: the intake during heat treatment [10,11], especially when involving austenitizing processes, as hydrogen solubility increases with temperature and in the presence of austenite (Figure 2); and absorption from an electrolyte [12], like acidic media [13] from cleaning and pickling processes or from electrolytic coating processes as in zinc plating [14].

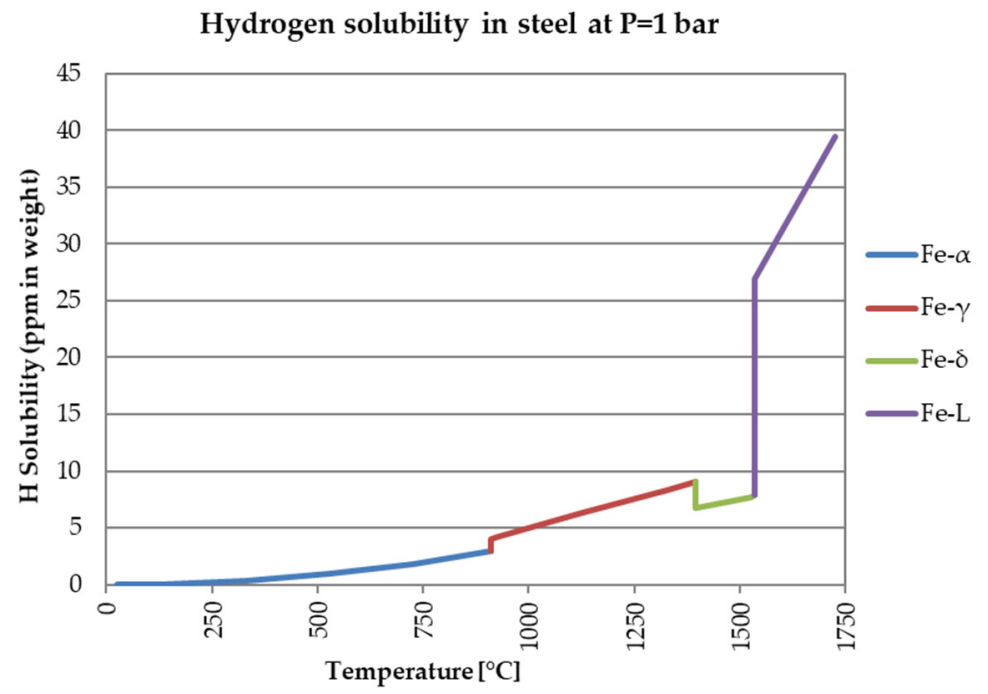

Figure 2. Solubility of $\mathrm{H}$ in iron at P-1 bar (made from [15]). 
External hydrogen can be incorporated into the steel when the steel is working under high $\mathrm{H}_{2}$ partial pressures [16] or under acidic conditions, among which sour service with $\mathrm{H}_{2} \mathrm{~S}$ stands out and has led to the existence of a very specific regulation [17]. A more common source of external hydrogen is the intake from an electrolyte both when impressed current cathodic protection systems and sacrificial coatings are used (e.g., zinc plating or hot dip galvanizing) $[18,19]$. These processes involving external hydrogen leading to what is known as Environmentally Assisted Cracking (EAC).

Figure 3 shows free corrosion and how galvanic protection processes lead to EAC, in the case of steels working in wet conditions. In free corrosion, iron dissolves in the water as $\mathrm{Fe}^{2+}$ ion donating two free electrons. These electrons recombine involving $\mathrm{H}^{+}, \mathrm{OH}^{-}$and $\mathrm{H}_{2} \mathrm{O}$. When there is an oxygen excess $\mathrm{Fe}_{2} \mathrm{O}_{3}$ forms on the steel surface. The reduction of $\mathrm{H}^{+}$to atomic $\mathrm{H}$ does not occur and EAC is avoided. For zinc coated steel in wet service with a discontinuity that exposes the steel substrate, the galvanic potential between the zinc anode and the steel cathodic zone is negative enough to allow hydrogen ion reduction, and drives a $\mathrm{H}^{+}$current to the steel surface, where atomic hydrogen can undergo the reaction of the $\mathrm{H}^{+}$ion with an electron to yield adsorbed molecular $\mathrm{H}$ on the steel surface. From there, the hydrogen enters the steel by diffusion.
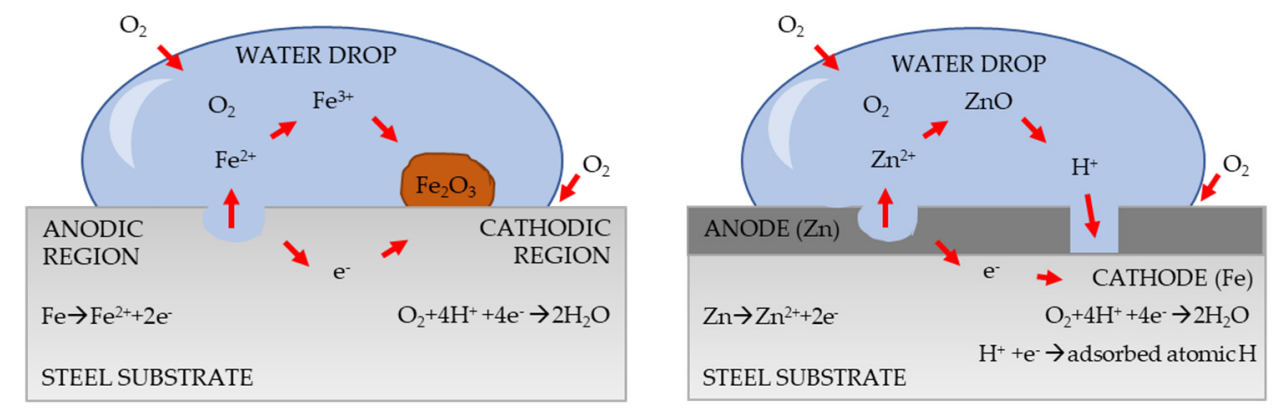

Figure 3. Hydrogen involving reactions in naked (left) and zinc coated (right) steel in contact with water.

The hydrogen then distributes inside the steel in form of diffusible and trapped hydrogen, the difference being the ability of the hydrogen atoms to move or not across the microstructure [20-22]. The fraction of diffusible hydrogen from the total hydrogen is known to affect EAC, as diffusion allows $\mathrm{H}$ atoms to accumulate in the maximum stress triaxiality sites of the material. Thus, hydrogen trap control has become a key resource to develop EAC resistant steels as demonstrated by Fielding [23] and Yamasaki [24]. With a similar approach, as diffusible hydrogen excess tends to effuse from the material when temperature is raised at oven temperatures, oven degassing treatments are industrially used to assess if steel integrity has been compromised by hydrogen [9,25], and this approach is used in this work. More specifically, the Slow Strain Rate Tensile testing (SSRT) results of specimens that have been oven dehydrogenated, compared to non-dehydrogenated, have been used to determine whether internal or external hydrogen was the cause of an in-field failure of a set of galvanized bolts.

The bolt in Figure 4 shows the actual HE case that motivates this study. It is a hot dip galvanized M52 class 10.9 bolt that was installed in an outdoors structure in a coastal onshore location in Northern Spain. The structure consisted of 90 bolts from the same batch and the fractured bolt is part of a set of seven bolts that suffered delayed fracture after a week in service at the same site. All the bolts were tightened with a dynamometric wrench to the desired fastening torque. The torque was calculated to reach the design clamping force of the joint, employing the measured friction coefficient between the bolt and the nut greased threads. The bolt-nut batch had passed regular quality control checks and no deviation was found in the fractured products; they were free of forging defects, decarburization, liquid metal embrittlement or quench cracking. 

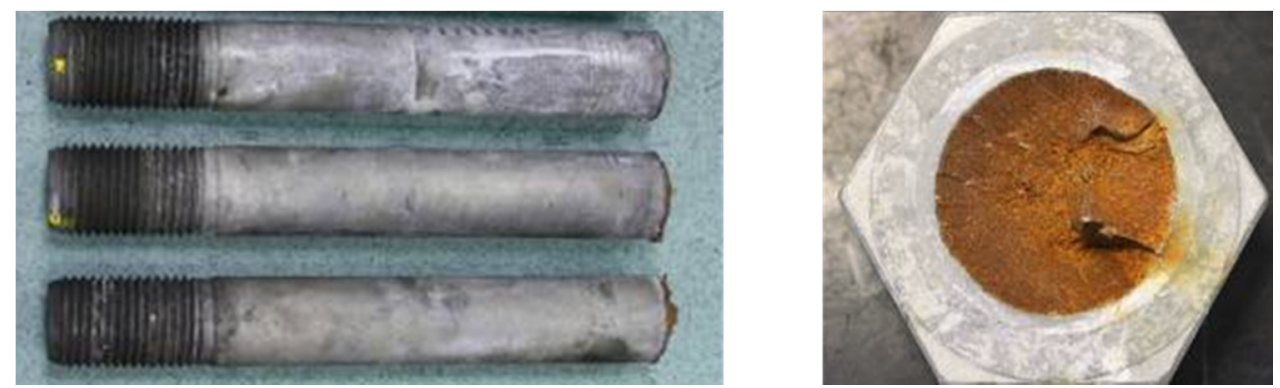

Figure 4. M52 class 10.9 bolt that failed in service due to delayed fracture.

When the failure surface of the cracked bolts was inspected, a trans-granular brittle cleavage pattern was observed, which is shown in Figure 5a, while the expected fractographic texture for the bolt corresponds to a ductile failure pattern like that shown in Figure 5b.
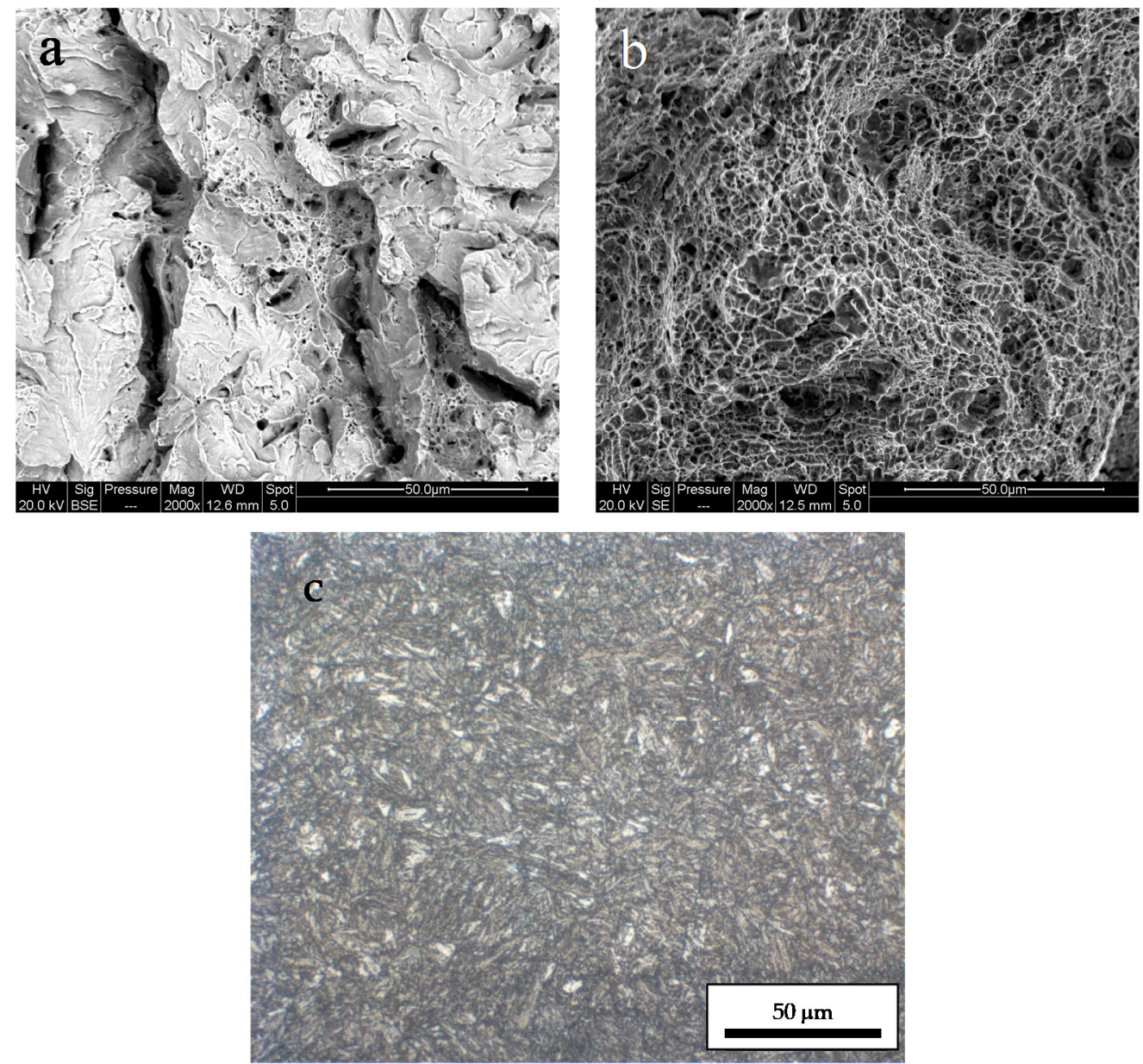

Figure 5. (a) Brittle cleavage texture in the crack surface of the M50 class 10.9 bolt shown in Figure 1; (b) ductile collapse texture in the tensile specimens extracted from the shaft of the same bolt; (c) microstructure of the bolt in the center of the shaft diameter.

This type of delayed fracture has been reported in hot dip galvanized bolts with sections fully immersed in water [26], EAC being the root cause of failure. The failed bolts of concern in this case study, though, were not immersed in water. Thus, this work is aimed at answering the following question: was the delayed fracture due to HE from internal hydrogen introduced by the manufacturing process or was it due to EAC from external hydrogen taken up in a scenario of water drop condensation on coating discontinuities at the bolt surface? 
With this question in mind, a SSRT based study was performed with the same material supply of fractured bolts. Tests on dehydrogenated and non-dehydrogenated samples were performed at different stages of the industrial production process (delivery condition, heat treatment and galvanizing) and, for the galvanized specimens were tested, both immersed in seawater and in dry conditions.

\section{Materials and Methods}

The material employed for the study is steel grade 30MnB5 according to UNE-EN 10083-3 [27] in bright bar format according to UNE-EN 10263-4 [28]. The material was received with dimensions of $\phi 48 \mathrm{~mm} \times 450 \mathrm{~mm}$ length (Figure 6) and in the usual condition of raw material for the manufacture of bolts. This material was sourced from the same mill as the fractured M52 bolts that motivated this study.

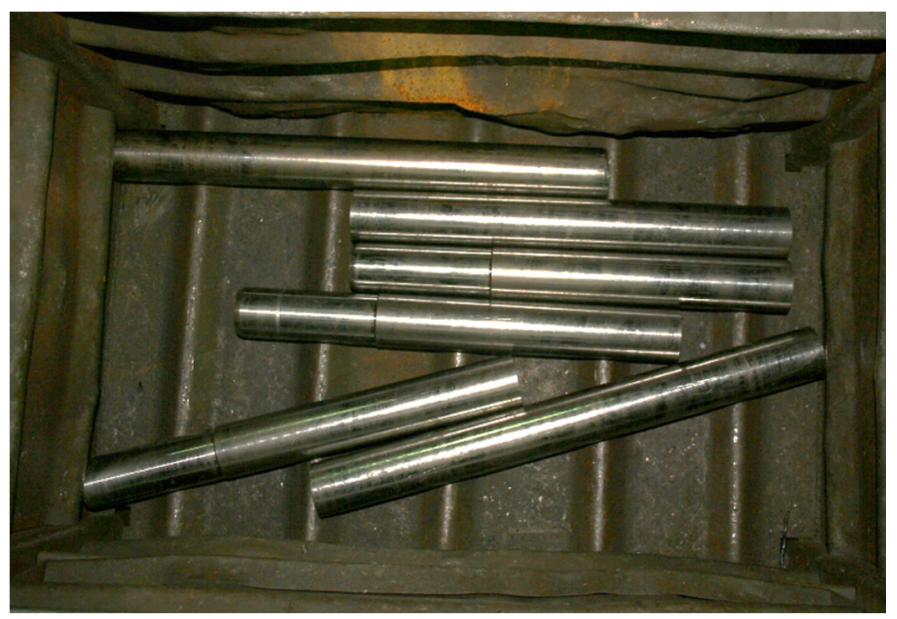

Figure 6. 30MnB5 bars employed for the study.

The chemical composition of the material was checked during incoming inspection. Table 1 shows the result of the analyses performed by spark spectrometry, with an expanded measurement uncertainty $(\mathrm{K}=2)$ of $\pm 0.03 \%$ for all the elements of the table. It is noted that the material meets the specifications set for alloyed quench and tempering steels under the designation 30MnB5, except for a slight excess in Mn content. The observed addition of $\mathrm{Cr}$ is intended to improve hardenability and is in accordance with the limits imposed by the current regulations [27], which allow the 30MnB5 nomenclature to be maintained.

Table 1. Chemical composition check (by weight $\%$ ) of 30MnB5 bars.

\begin{tabular}{ccccccccc}
\hline Sample & & C & Si & Mn & P & S & Cr & B \\
\hline Specimens & & 0.29 & 0.24 & 1.49 & $<0.015$ & $<0.005$ & 0.50 & 0.0026 \\
\hline Specification & Min. & 0.27 & - & 1.15 & - & - & - & 0.0008 \\
30MnB5 & Max. & 0.33 & 0.40 & 1.45 & 0.025 & 0.035 & $* *$ & 0.0050 \\
\hline Class requirements & Min. & 0.20 & - & - & - & - & - & - \\
$8.8 / 9.8 / 10.9$ & Max. & 0.55 & - & - & 0.025 & 0.025 & - & 0.003 \\
\hline
\end{tabular}

* Results of the chemical analysis performed on the bars by spark emission spectroscopy. ${ }^{* *}$ Additions up to $2 \% \mathrm{Cr}$ permissible by standard [27] for improved hardenability.

The material also meets the chemical composition requirements established for Class 8.8 to 10.9 [29] fasteners. It should be remembered that the bolt classes are determined mainly by the resistance levels as shown in Table 2. 
Table 2. Nominal values of mechanical properties for high-strength bolt classes [29].

\begin{tabular}{ccccc}
\hline Class & $\begin{array}{c}\text { Yield Strength } \\
\mathbf{R}_{\mathbf{p} 0.2} \mathbf{( M P a )}\end{array}$ & $\begin{array}{c}\text { Ultimate Tensile Strength } \\
\mathbf{R}_{\mathbf{m}} \mathbf{( M P a )}\end{array}$ & $\begin{array}{c}\text { Elongation } \\
\mathbf{E ~ ( \% )}\end{array}$ & $\begin{array}{c}\text { Reduction in Area } \\
\mathbf{R A} \mathbf{( \% )}\end{array}$ \\
\hline 8.8 & $>640$ & $>800$ & $>12$ & $>52$ \\
9.8 & $>720$ & $>900$ & $>10$ & $>48$ \\
10.9 & $>900$ & $>1000$ & $>9$ & $>48$ \\
12.9 & $>1080$ & $>1200$ & $>8$ & $>44$ \\
\hline
\end{tabular}

For the study of internal hydrogen uptake during the production process, 27 specimens were prepared and divided into three sets of specimens, one for each stage of production (Figure 7):

- Seven specimens were used to study the supply condition of the raw material.

- Twenty were subjected to a quench and tempering treatment in industrial installations accompanying a 30MnB5 and class $10.9 \mathrm{M} 32$ bolt manufacturing order. Seven of these fourteen were used to study internal hydrogen uptake during heat treatment and three for submerged testing.

- The remaining ten heat treated specimens were hot dip galvanized in industrial installations accompanying the same 30MnB5 and Class 10.9 M32 bolt manufacturing order. Seven were used to study internal hydrogen uptake in the galvanizing process and three for submerged testing.

The quench and tempering sequence that was applied is reported below, and it reproduces that of the fractured M52 bolts that motivated this work (same furnaces and processing conditions):

- Austenitizing in a continuous furnace at a setpoint of $875{ }^{\circ} \mathrm{C}$ with a dwell time of $30 \mathrm{~min}$. The carbon activity was controlled in the atmosphere to prevent decarburization.

- Oil quenching.

- Tempering in a continuous furnace set at $540{ }^{\circ} \mathrm{C}$ for a dwell time of $120 \mathrm{~min}$ followed by air cooling, accompanying the same load industrial load of M32 bolts. The furnace atmosphere was controlled to prevent decarburization.

Non-acidic surface conditioning (cleaning, etching and rinsing) and hot dip galvanizing was performed in an industrial production facility.

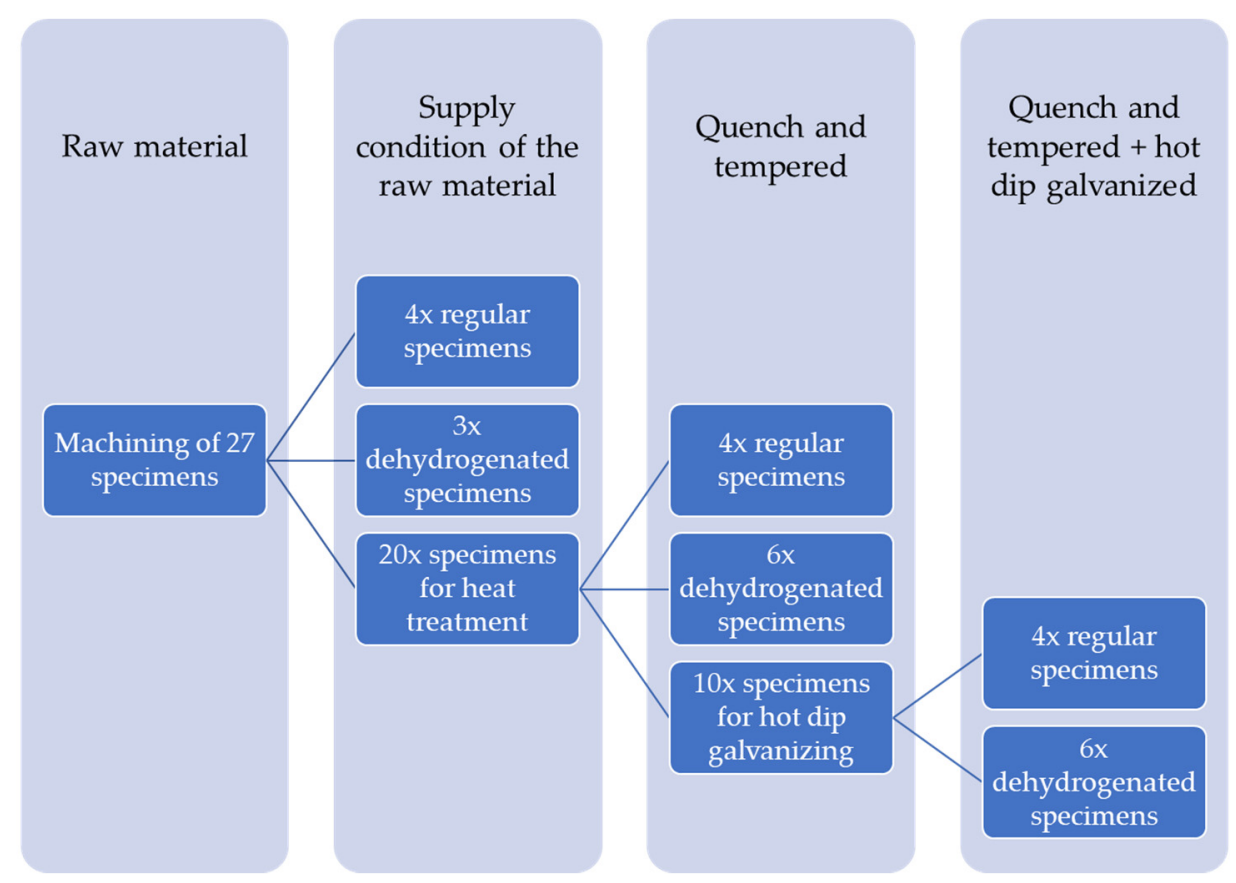

Figure 7. Materials for the study of internal hydrogenation in the manufacturing process for class 10.9 bolts. 
Three specimens from each set were submitted to SSRT in air at room temperature without applying a dehydrogenating treatment, while the other three were dehydrogenated in an oven at $250^{\circ} \mathrm{C}$ for $2 \mathrm{~h}$ before being tested under the same conditions. This baking process at $250{ }^{\circ} \mathrm{C}$ is considered sufficient to express a drop in the diffusible hydrogen from the material affected by delayed fracture [9], if any. A loss of ductility of non-conditioned samples relative to dehydrogenated samples would indicate the presence of diffusible hydrogen, incorporated into the material during the production process.

For the heat treated and galvanized specimens, three further specimens were dehydrogenated to perform SSRT immersed in seawater, to assess the severity of the EAC produced by the concurrence of the zinc coating and water. All tests were carried out at room temperature $\left(23^{\circ} \mathrm{C}\right)$. Table 3 summarizes the tests that were performed, indicating the identification code that will be used to refer to each material and testing condition in the following.

Table 3. Summary of the tensile testing battery.

\begin{tabular}{|c|c|c|c|c|c|}
\hline Identification & Description & Conditioning & Testing Media & Type of Test & Repeats \\
\hline $\mathrm{DC}$ & \multirow{3}{*}{ Delivery Condition } & \multirow{2}{*}{ Non Dehydrogenated } & \multirow{3}{*}{ Air } & Regular Tensile & 1 \\
\hline DC-ND & & & & \multirow{2}{*}{ SSRT } & 3 \\
\hline DC-DH & & Dehydrogenated & & & 3 \\
\hline QT & \multirow{4}{*}{$\begin{array}{l}\text { Quench and } \\
\text { Tempered }\end{array}$} & \multirow{2}{*}{ Non Dehydrogenated } & \multirow{3}{*}{ Air } & Regular Tensile & 1 \\
\hline QT-ND & & & & \multirow{3}{*}{ SSRT } & 3 \\
\hline QT-DH & & \multirow{2}{*}{ Dehydrogenated } & & & 3 \\
\hline QT-SW & & & Seawater & & 3 \\
\hline GA & \multirow{4}{*}{$\begin{array}{l}\text { Quench and } \\
\text { tempered + Hot-dip } \\
\text { GAlvanized }\end{array}$} & \multirow{2}{*}{ Non Dehydrogenated } & \multirow{3}{*}{ Air } & Regular Tensile & 1 \\
\hline GA-ND & & & & \multirow{3}{*}{ SSRT } & 3 \\
\hline GA-DH & & \multirow{2}{*}{ Dehydrogenated } & & & 3 \\
\hline GA-SW & & & Seawater & & 3 \\
\hline
\end{tabular}

As is shown in Table 3, one specimen per set was tested under conventional tensile testing conditions [30] to verify that the material performance was as expected and to accept the material condition for further testing. The results of these tests are presented in Table 4. It is noted that the bars in delivery condition could be used directly to manufacture Class 8.8 bolts. After heat treatment, the specimens met the mechanical requirements for class 10.9 bolts as expected. It is important to stress that the heat treatments were carried out in all cases on specimens already machined and not on bars, so that the detection of surface effects caused by the process was not hidden by further machining and it was verified that the control of the protective atmosphere of the furnace had been correct (absence of carburized or decarburized layer).

Table 4. Verification of the mechanical properties of 30MnB5 samples. The tolerances correspond to the expanded measurement uncertainty of each result $(K=2)$.

\begin{tabular}{|c|c|c|c|c|c|}
\hline \multicolumn{2}{|c|}{ Identification } & $\begin{array}{l}\text { Yield Strength } \\
\mathrm{R}_{\mathrm{p} 0.2}(\mathrm{MPa})\end{array}$ & $\begin{array}{l}\text { Ultimate Tensile Strength } \\
\qquad \mathbf{R}_{\mathbf{m}}(\mathbf{M P a})\end{array}$ & $\begin{array}{l}\text { Elongation } \\
\text { E (\%) }\end{array}$ & $\begin{array}{c}\text { Reduction in Area } \\
\text { RA (\%) }\end{array}$ \\
\hline \multicolumn{2}{|c|}{ DC } & $734 \pm 7$ & $847 \pm 9$ & $13.9 \pm 1.5$ & $54 \pm 1$ \\
\hline \multicolumn{2}{|c|}{ QT } & $1038 \pm 10$ & $1100 \pm 11$ & $15.1 \pm 1.5$ & $67 \pm 1$ \\
\hline \multicolumn{2}{|c|}{ GA } & $1037 \pm 10$ & $1097 \pm 11$ & $12.4 \pm 1.5$ & $55 \pm 1$ \\
\hline \multirow{2}{*}{ Specification } & Class 8.8 & $>640$ & $>800$ & $>12$ & $>52$ \\
\hline & Class 10.9 & $>900$ & $>1000$ & $>9$ & $>48$ \\
\hline
\end{tabular}

The media used in submerged specimen tests was a seawater substitute according to ASTM D1141 [31]. All electrolytes used for the experimental part of this work were prepared in accordance with this standard in the heavy metal version and with the composition indicated in Table 5. The distilled 
water used as the base of the mixture met in all preparations the level of purity required by ASTM D1193 [32], Type II. The pH of the electrolyte was adjusted in all cases to $8.2 \pm 0.1$ by additions of $\mathrm{NaOH} 0.1 \mathrm{~N}$ after the compound mixing process was complete.

Table 5. Chemical composition of synthetic seawater employed in the tests.

\begin{tabular}{cc}
\hline Compound & Concentration $(\mathrm{g} / \mathrm{L})$ \\
\hline $\mathrm{NaCl}$ & 24.53 \\
$\mathrm{MgCl}_{2}$ & 5.20 \\
$\mathrm{Na}_{2} \mathrm{SO}_{4}$ & 4.09 \\
$\mathrm{CaCl}_{2}$ & 1.16 \\
$\mathrm{KCl}$ & 0.695 \\
$\mathrm{NaHCO}$ & 0.201 \\
$\mathrm{KBr}$ & 0.101 \\
$\mathrm{H}_{3} \mathrm{BO}_{3}$ & 0.027 \\
$\mathrm{SrCl}$ & 0.025 \\
$\mathrm{NaF}_{2}$ & 0.003 \\
$\mathrm{Ba}\left(\mathrm{NO}_{3}\right)_{2}$ & 0.0000994 \\
$\mathrm{Mn}\left(\mathrm{NO}_{2}\right)_{2}$ & 0.0000340 \\
$\mathrm{Cu}\left(\mathrm{NO}_{3}\right)_{2}$ & 0.0000308 \\
$\mathrm{Zn}\left(\mathrm{NO}_{3}\right)_{2}$ & 0.0000096 \\
$\mathrm{~Pb}\left(\mathrm{NO}_{3}\right)_{2}$ & 0.0000066 \\
$\mathrm{AgNO}_{3}$ & 0.00000049 \\
\hline
\end{tabular}

The SSRT method employed for the assessment of process hydrogenations and zinc coating induced EAC is explained in ASTM G129-00 [33]. This method consists of a test analogous to that of uniaxial tensile testing, but at a very low strain rate. Using a reduced deformation rate (e.g., $10^{-5} \mathrm{~s}^{-1}$ ) is a key element in the case of studying external embrittlement processes as in this work, as it allows hydrogen distribution to evolve in the microstructure. In conventional tensile test speeds, are at least an order of magnitude faster [30] than in slow strain rate tests, and hydrogen absorption kinetics and diffusion kinetics are not able to modify material behavior and therefore do not allow hydrogen embrittlement to be assessed. It is important to remark that SSRT results are comparative in nature, i.e., they are used to determine whether one material behaves better than another in the same embrittling conditions, or whether the same material has different susceptibility to HE in two different hydrogenation environments. For this reason, the SSRT results are usually provided as a ratio between the values obtained for the condition of interest and a control condition against which it is compared.

The SSRT were performed on a Zwick Roell Model 1475 universal machine (Zwick Roell, Ulm, Germany) with a maximum load capacity of $100 \mathrm{kN}$. Circular cross-sectional specimens of $\phi 10 \mathrm{~mm}$ were used according to UNE EN-ISO 6892-1:2017 (Figure 8).

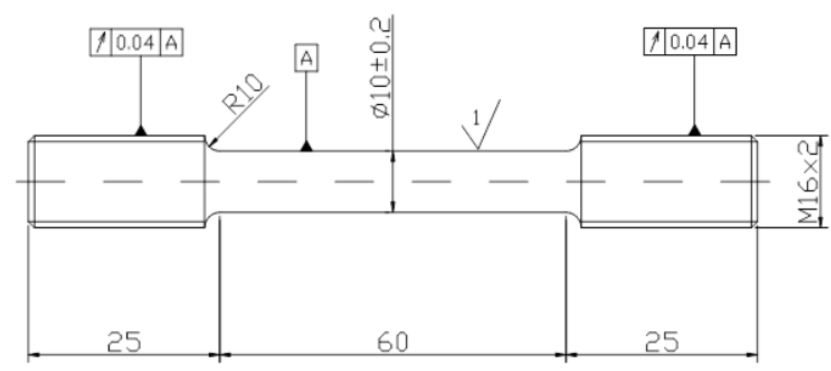

Figure 8. Manufacturing sketches of the specimens used in tests at low deformation speed. Dimensions in $\mathrm{mm}$.

The 30MnB5 steel specimens were obtained from bars of $\phi 48 \mathrm{~mm}$ as shown in Figure 9. The heat treatments and galvanizing were applied directly to the specimens. In this way, the skin of the tested 
material reproduces the working condition of interest, like that of the commercial bolts whose failure motivated this work.

The tests were carried out in all cases with a crosshair feed of $0.03 \mathrm{~mm} / \mathrm{min}$, which corresponds to a strain rate of $10^{-5} \mathrm{~s}^{-1}$.

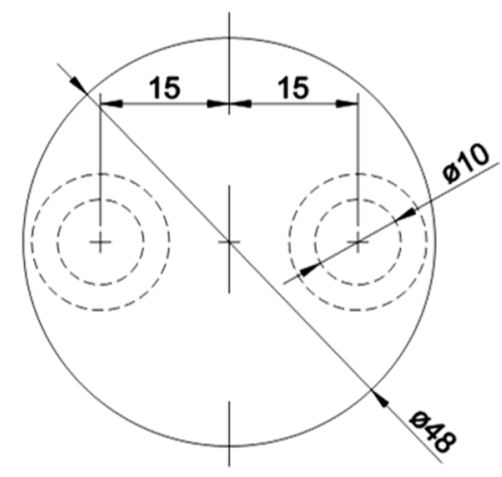

Figure 9. Specimen extraction sketch of bolt steel specimens. Dimensions in $\mathrm{mm}$.

\section{Results and Discussion}

The average results of the SSRT tests targeted to assessing the HE at different stages of the manufacturing process are shown in Table 6. These tests were performed in air. It should be noted that these averages are calculated on three specimens and, to avoid generating a sense of false accuracy, experimental deviations corresponding to the $95 \%$ confidence interval on the average have been included using the expression (1).

$$
I C 95= \pm \sqrt{(U(K=2))^{2}+\left(\frac{t_{\propto=0.05,2} \cdot S_{v}}{\sqrt{3}}\right)^{2}}
$$

where $U(K=2)$ is the expanded uncertainty of each individual measure, $t_{\propto}=0.05,2$ is the value of Student's $t$ for a significance value of $0.05 \%$ in a distribution of two tails and two degrees of freedom and $S_{v}$ is the standard deviation.

Table 6. Average values of mechanical properties obtained in SSRT at different stages of the production process of class 10.9 bolts with 30MnB5 steel.

\begin{tabular}{ccccc}
\hline Identification & $\begin{array}{c}\text { Yield Strength } \\
\mathbf{R}_{\mathbf{p 0 . 2}} \mathbf{( M P a )}\end{array}$ & $\begin{array}{c}\text { Ultimate Tensile Strength } \\
\mathbf{R}_{\mathbf{m}} \mathbf{( M P a )}\end{array}$ & $\begin{array}{c}\text { Elongation } \\
\mathbf{E ~ ( \% )}\end{array}$ & $\begin{array}{c}\text { Reduction in Area } \\
\mathbf{R A ~ ( \% )}\end{array}$ \\
\hline DC-ND & $720 \pm 25$ & $841 \pm 19$ & $13.7 \pm 1.7$ & $51.4 \pm 7.9$ \\
DC-DH & $756 \pm 27$ & $850 \pm 25$ & $12.9 \pm 1.8$ & $52.2 \pm 9.6$ \\
QT-ND & $1022 \pm 31$ & $1091 \pm 23$ & $14.0 \pm 2.5$ & $62.9 \pm 6.4$ \\
QT-DH & $1013 \pm 19$ & $1085 \pm 18$ & $14.0 \pm 1.7$ & $62.5 \pm 3.9$ \\
GA-ND & $1016 \pm 36$ & $1087 \pm 19$ & $13.4 \pm 3.3$ & $58.4 \pm 5.4$ \\
GA-DH & $1007 \pm 17$ & $1069 \pm 52$ & $13.3 \pm 1.6$ & $60.7 \pm 1.3$ \\
\hline
\end{tabular}

To evaluate if a step in the process had caused any significant change in HE, the results in Table 6 were analyzed by hypothesis tests which were performed for the difference in the averages of normal distributions. The hypothesis tests concerned all the four SSRT outputs considered in this work, $R_{p 0.2}$, $\mathrm{R}_{\mathrm{m}}$, E and RA with a significance level of $\alpha=0.01$. The conditions that were chosen for the analyses are the following:

- $\quad$ DC-ND versus DC-DH: to assess the possible HE incoming from the hot rolling process.

- QT-ND versus QT-DH: to assess whether there was any HE caused by heat treatment or not.

- GA-ND versus GA-DH: to assess if the galvanizing process caused any HE. 
- QT-ND versus GA-ND and QT-DH versus GA-DH: to assess if galvanizing modified the mechanical behavior from the heat-treated condition.

There is no statistically significant difference between the average values of the experimental data in any of the comparisons stated above. Thus, no effect of the production process can be associated with HE.

Figure 10 has been elaborated to help in visualizing this fact. It plots the average values in Table 6 with their standard deviation as the parameters of Normal probability distribution functions. Starting with the values of strength, the results have been divided first by class and then by condition. Figure 10a shows, that for the raw material in delivery condition, $R_{m}$ distributions overlap by a high percentage, while $\mathrm{R}_{\mathrm{p} 0.2}$ coincide in about $50 \%$ of their dispersion. Accounting for the reduced number of repeats, this $50 \%$ overlapping has been enough to discard the existence of statistically significant differences between the averages of $\mathrm{R}_{\mathrm{p} 0.2}$ for DC-ND and DC-DH.

The plots in Figure 10b represent the averages for QT and GA specimen sets. These curves are similar to those of DC specimens in the sense that the curves overlap at a high percentage. This fact removes the possibility of affirming that the difference observed between the means is significant, even for the most disperse values such as $\mathrm{R}_{\mathrm{m}}$ on GA-DH when working with three repeats.

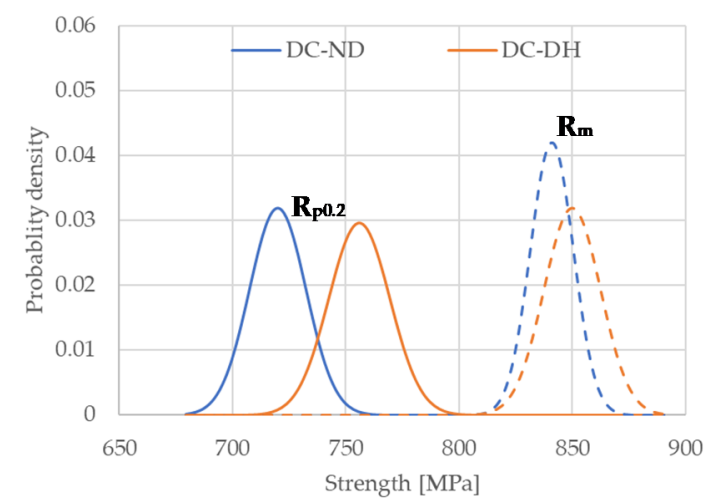

(a)

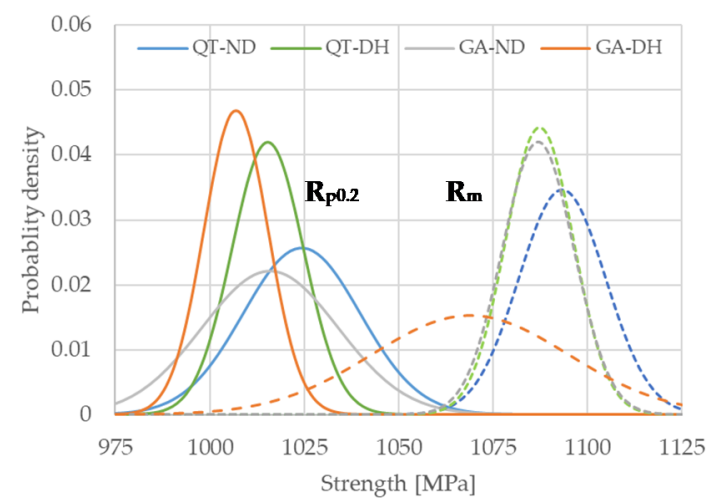

(b)

Figure 10. Probability density plot assuming Normal distribution of average strengths and their uncertainties in Table 6 as mean and standard deviation values. (a) Plot for the DC Class 8.8 specimens. (b) Plot for the QT and GA Class 10.9 specimens.

The same plotting approach for E and RA is shown in Figure 11. For these two properties, which are highly affected by HE and EAC, the curve overlapping is even higher than that for the strengths. This confirms that no major mechanical property decay due to production process-related internal hydrogen HE was produced in the original M52 fractured bolts that motivated this work. Major decays would have been detected even with three repeats.

Regarding the SSRT tests in seawater, targeted to assess the weight of EAC in the failure of the fractured M52 bolts, Table 7 gathers the obtained average results. In this case, the hypothesis tests were again performed in terms of the existence of a difference in the average of the results. The following results were compared:

- QT-DH versus QT-SW: to assess if the immersion in seawater causes any noticeable EAC in the absence of the galvanic protection coating.

- GA-DH versus GA-SW: to assess if the immersion in seawater causes any noticeable EAC in the presence of the galvanic protection coating. 


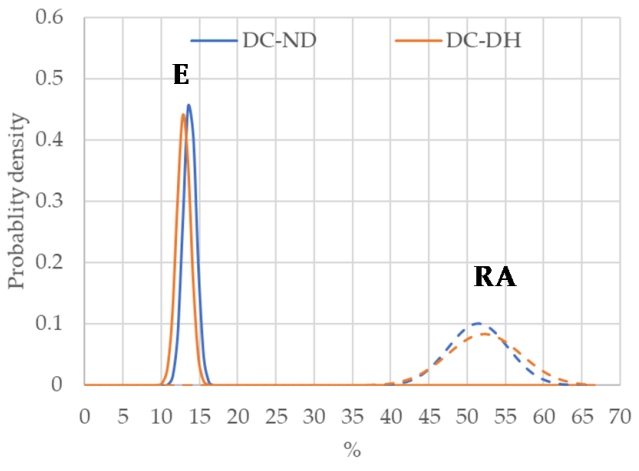

(a)

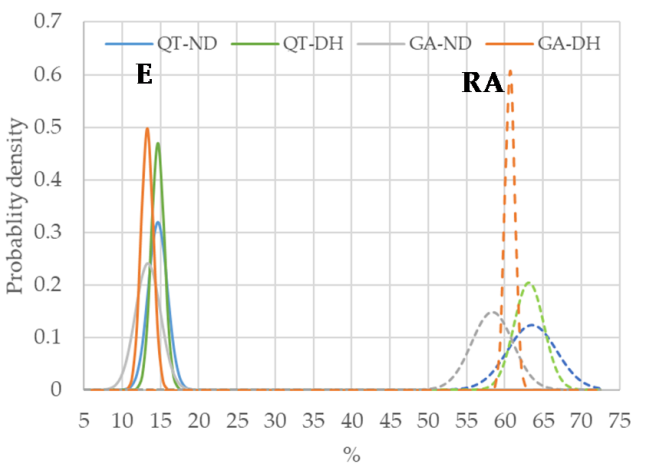

(b)

Figure 11. Probability density plot assuming Normal distribution of average elongations and area reduction and their uncertainties in Table 6 as mean and standard deviation values. (a) Plot for the DC Class 8.8 specimens. (b) Plot for the QT and GA Class 10.9 specimens.

Table 7. Average values of the mechanical properties obtained in water submerged SSRT with 30MnB5 steel treated to class 10.9 bolt strength, both for naked and hot-dip galvanized specimens.

\begin{tabular}{ccccc}
\hline Condition & $\begin{array}{c}\text { Yield Strength } \\
\mathbf{R}_{\mathbf{p 0 . 2}} \mathbf{( M P a )}\end{array}$ & $\begin{array}{c}\text { Ultimate Tensile Strength } \\
\mathbf{R}_{\mathbf{m}} \mathbf{( M P a )}\end{array}$ & $\begin{array}{c}\text { Elongation } \\
\text { E (\%) }\end{array}$ & $\begin{array}{c}\text { Reduction in Area } \\
\text { RA (\%) }\end{array}$ \\
\hline QT-SW & $1014 \pm 10$ & $1087 \pm 23$ & $13.8 \pm 2.6$ & $61.7 \pm 4.2$ \\
GA-SW & $1018 \pm 20$ & $1090 \pm 26$ & $11.3 \pm 3.8$ & $43.6 \pm 6.8$ \\
\hline
\end{tabular}

The outcome of the statistical analysis indicates that the effect of the immersion is not significant in terms of strength for either of the conditions; neither naked (QT), nor galvanized (GA). Figure 12 reflects this fact, as the gaussian curves overlap clearly for QT (Figure 12a) and slightly less so for GA (Figure 12b) specimens. The most doubtful result is observed for $R_{m}$ in GA-DH and GA-SW, but again about $50 \%$ of the curve overlaps in the worst case and three repeats do not allow the conclusion that this is a significant variation.

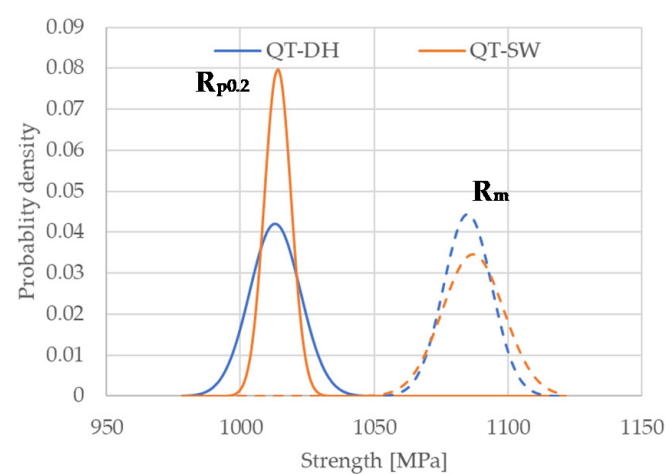

(a)

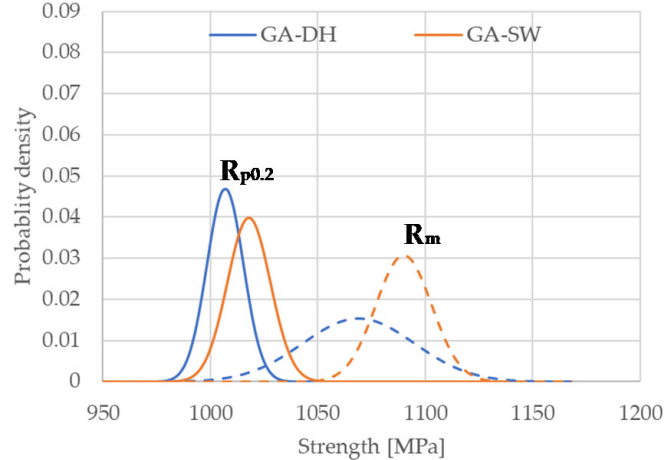

(b)

Figure 12. Probability density plot assuming Normal distribution of average strengths and their uncertainties in Table 7 as mean and standard deviation values. (a) Plot for the QT specimens. (b) Plot for GA specimens.

When the hypothesis tests are performed on the difference of averages of the ductility related properties, the scenario changes, not for the elongation, E, but for the reduction in area, RA. The outcome of the statistical analysis is that the drop in the average RA is significant for the galvanized specimens tested in submerged condition, with a level of significance of $\alpha=0.01$. Figure 13 plots this: the RA curves of the graph in Figure 13a show that the Gaussian for GA-DH and the Gaussian for GA-SW do not touch each other. Consequently, it is statistically sound to affirm that an embrittlement process has 
been developed in the GA-SW SSRT specimens and their differences in both E and RA can be considered as an actual effect of EAC and not a statistical artifact. This combination of hot dip galvanizing Zn coatings and water as the critical factor for the failure of bolts in the field has been reported by other case studies $[26,34]$.

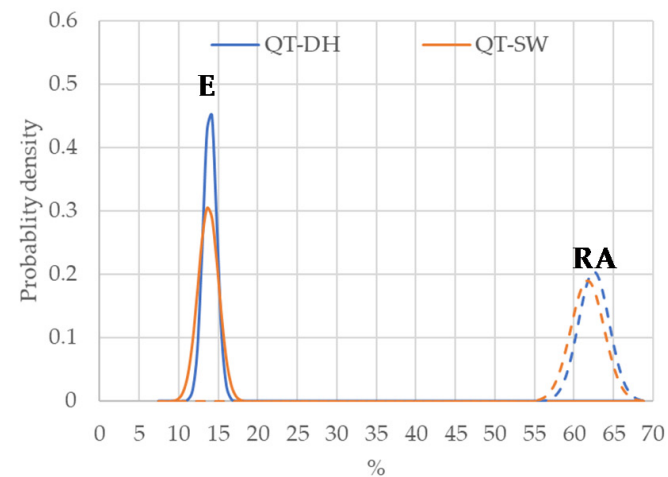

(a)

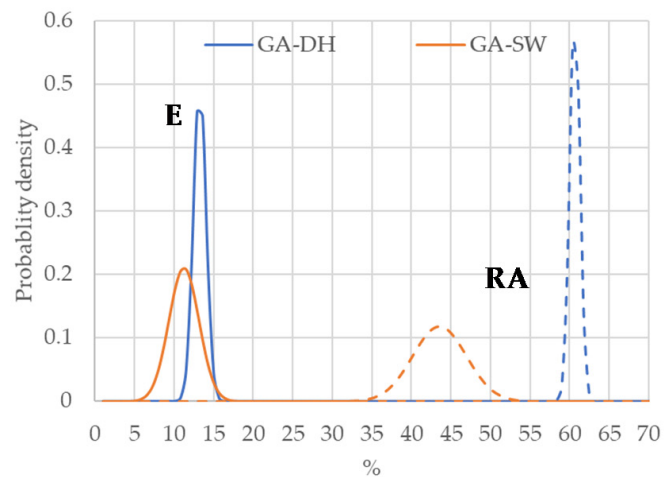

(b)

Figure 13. Probability density plot assuming a Normal distribution of average strengths and their uncertainties in Table 7 as mean and standard deviation values. (a)Plot for the QT specimens. (b) Plot for GA specimens.

Once the presence of EAC is confirmed, it is possible to assess the embrittlement susceptibility of the GA-SW condition, employing the embrittlement ratios as indicated in the standard testing method ASTM G129. The embrittlement ratios measured in this case for the average E and RA values in GA-SW condition using GA-DH as control condition are $85 \%$ and $72 \%$ respectively (Table 8 ).

Table 8. Embrittlement susceptibility ratios for the GA-SW condition.

\begin{tabular}{cccc}
\hline Control Condition & EAC Condition & $\mathbf{R E}=\mathbf{E}_{\mathrm{GA}-\mathrm{SW}} / \mathrm{E}_{\mathrm{GA}-\mathrm{DH}}$ & $\mathbf{R R A}=\mathbf{R A}_{\mathrm{GA}-\mathrm{SW}} / \mathbf{R A}_{\mathrm{GA}-\mathrm{DH}}$ \\
\hline GA-DH & GA-SW & $85 \%$ & $72 \%$ \\
\hline
\end{tabular}

The EAC was also confirmed by visual inspection of the fractured SSRT specimens (Figure 14). Only GA-SW specimens showed a very severe cracking pattern all along the necking section. The cracks caused by EAC appear remarked in white, due to material deposition from the electrolyte in the areas of the substrate exposed by the appearance of the cracks themselves. Similar EAC cracking patterns had been observed in previous work [18] for steels with the same strength level as the GA-DH specimens, when a cathodic protection potential was applied to seawater immersed SSRT.

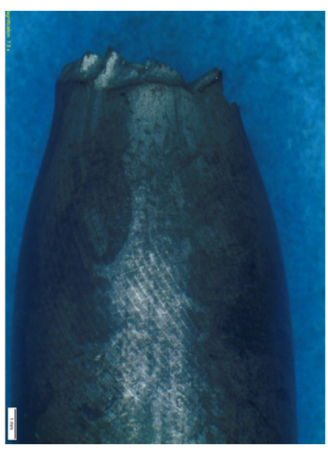

QT-DH

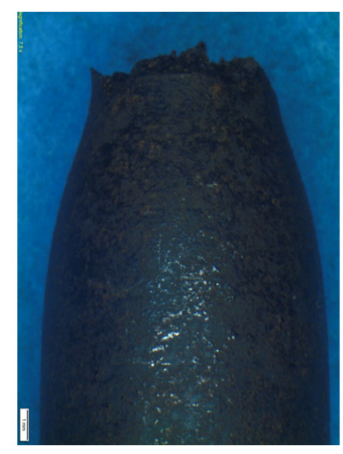

QT-SW

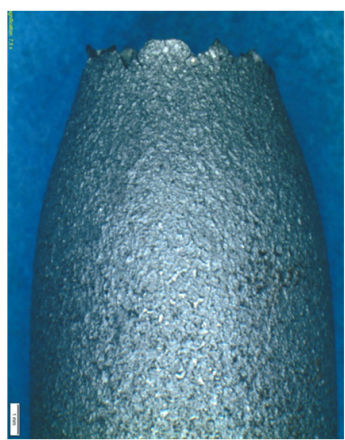

GA-DH

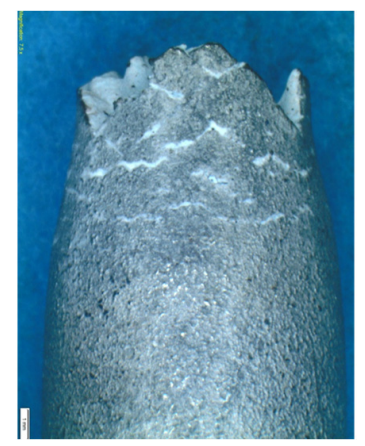

GA-SW

Figure 14. Pictures of the necking areas of representative SSRT specimens showing no EAC except for GA-SW. 


\section{Conclusions}

Tensile testing specimens were manufactured following exactly the same raw material grade and source, and the same industrial manufacturing route (same suppliers and process parameters), as a set of class 10.9 hot-dip galvanized M52 bolts that had suffered a delayed fracture. The intention was to elucidate whether the fracture was HE affected by internal hydrogen uptake of the bolts during their manufacture, or was an EAC issue affected by external hydrogen uptake of the bolts due to the water condensation on a discontinuity of the zinc coating. The results have made clear that the industrial production process does not promote the presence of internal HE in the studied steps: the supply condition of the raw material, the heat treatment, and the hot-dip galvanizing. The specimens processed according to the production route did not require subsequent dehydrogenation processes. Though this does not ensure that there cannot be a mistake in the supply chain, it at least shows the right capability and points to external hydrogen as the principal process involved in the failure of the M52 bolts.

Regarding EAC, it has been observed that mere immersion in seawater does not produce any embrittlement effect on the naked material, while the presence of a galvanic coating in this medium causes a significant susceptibility to EAC. In this particular case study of bolt delayed fracture, the evidence points to a combination of poor zinc coating condition (no matter whether from the galvanizing or due to scratching during poor handling) and the presence of condensation from seawater droplets or aerosol in the installation site (coastal Northern Spain) as the origin of the problem. As the EAC did not affect the whole installed bolt set, it is likely that some of the bolts were unscratched, as the whole batch was installed under the same ambient humidity. Though hydrogen induced fracture-preventing practices are usual in bolt industry, small details such as poor handling can still lead to premature failures. Even in the absence of coating defects, a sufficient coating thickness must be guaranteed, as thin zinc layers may eventually dissolve and expose the EAC susceptible steel substrate.

Author Contributions: Conceptualization, J.A. and G.A.; methodology, J.A. and G.A.; validation, G.A. and J.A.; formal analysis, G.A. and J.A.; writing-original draft preparation, G.A.; writing-review and editing, G.A. and J.A.; supervision, J.A. Both authors have read and agreed to the published version of the manuscript.

Funding: This research received no external funding.

Conflicts of Interest: The authors declare no conflict of interest.

\section{References}

1. Billingham, J.; Sharp, J.; Spurrier, J.; Kilgallon, P. Review of the Performance of High Strength Steels Used Offshore, HSE Books; TSO: London, UK, 2003.

2. Uno, N.; Kubota, M.; Nagata, M.; Tarui, T.; Kanisawa, H.; Azuma, K.; Miyagawa, T. Super-high-strength bolt “SHBT(R)". In Nippon Steel Technical Report; Nippon Steel Corporation: Tokyo, Japan, 2008; Volume 97, pp. 95-104.

3. Milella, P. Fatigue and Corrosion in Metals; Springer: Milan, Italy, 2013; pp. 689-729.

4. Anderson, T. Fracture Mechanics: Fundamentals and Applications; CRC Press: Boca Raton, FL, USA, 2005.

5. ASTM. F1940-07a Standard Test Method for Process Control Verification to Prevent Hydrogen Embrittlement in Plated or Coated Fasteners; American Society for Testing Materials: West Conshohocken, PA, USA, 2014.

6. ASTM. F1624-12 Standard Test Method for Measurement of Hydrogen Embrittlement Threshold in Steel by the Incremental Step Loading Technique; American Society for Testing Materials: West Conshohocken, PA, USA, 2012.

7. Bigeev, V.; Nikolaev, A.; Sychkov, A. Effect of the production factors on the hydrogen saturation of steel. Manuf. Ferr. Met. 2013, 6, 15-21. [CrossRef]

8. Ravinchandar, D.; Balausamy, T.; Gobinath, R.; Balanchandran, G. Behavior of hydrogen in industrial scale steel melts. Trans. Indian Inst. Metall. 2018. [CrossRef]

9. DNV-GL. DNVGL-OS-E302 Offshore Mooring Chain, Offshore Standard; Det Norske Veritas group: Oslo, Sweden, 2018. 
10. Zhang, M.; Wang, M.; Dong, H. Hydrogen absorption and desorption during heat treatment of AISI 4140 steel. J. Iron Steel Res. Int. 2014, 21, 951-955. [CrossRef]

11. Cho, L.; Sulistiyo, D.; Seo, E.; Jo, K.R.; Kim, S.; Oh, K.; Cho, Y.; De Cooman, B. Hydrogen absorption and embrittlement of ultra-high strength aluminized press hardening steel. Mater. Sci. Eng. A 2018, 734, 416-426. [CrossRef]

12. El-Yazgi, A.; Hardie, D. The embrittlement of a duplex stainless steel by hydrogen in a variety of environments. Corros. Sci. 1996, 38, 735-744. [CrossRef]

13. Elhoud, A.; Renton, N.; Deans, W. Hydrogen embrittlement of superduplex stainless steel in acid solution. Int. J. Hydrogen Energy 2010, 35, 6455-6464. [CrossRef]

14. Hardie, D.; Charles, E.; Lopez, A. Hydrogen embrittlement of high strength pipeline steels. Corros. Sci. 2006, 48, 4378-4385. [CrossRef]

15. Pasadani, R.; Strauch, D.; Wienkelman, J. Landölt-Borstein: Numerical data and functional relationships in science and technology-Group IV. Phys. Chem. 2017, 5. [CrossRef]

16. Murakami, Y. The effect of hydrogen on fatigue properties of metals used for fuel cell systems. Int. J. Fract. 2006, 138, 167-195. [CrossRef]

17. International Organization for Standardization. ISO 15156-1:2015 Petroleum and Natural Gas Industries-Materials for Use in H2S-Containing Environments in Oil and Gas Industries-Part 1: General Principles for Selection of Cracking-Resistant Materials; International Organization for Standardization: Geneva, Switzerland, 2015.

18. Artola, G.; Arredondo, A.; Fernández-Calvo, A.; Aldazabal, J. Hydrogen embrittlement susceptibility of R4 and R5 high strength mooring steels in cold and warm seawater. Metals 2018, 8, 700. [CrossRef]

19. Figueroa, D.; Robinson, M. The effects of sacrificial coating on hydrogen embrittlement and re-embrittlement of ultra-high strength steels. Corros. Sci. 2008, 50, 1066-1079. [CrossRef]

20. Nagumo, M. Fundamentals of Hydrogen Embrittlement; Springer Science + Bussiness Media: Singapore, 2016.

21. Poound, B. Hydrogen trapping in high-strength steels. Acta Mater. 1998, 46, 5733-5743. [CrossRef]

22. Liu, Y.; Wang, M. Hydrogen trapping in high strength martensitic steel after austenitized at different temperatures. Int. J. Hydrogen Energy 2013, 38, 14364-14368. [CrossRef]

23. Fielding, L.; Song, E.; Han, D.; Bhadeshia, H.; Suh, D.-W. Hydrogen diffusion and the percolation of austenite in nanostructured bainitic steel. Proc. R. Soc. A 2014, 470, 20140108. [CrossRef]

24. Yamasaki, S.; Bhadeshia, H. M4C3 precipitation in Fe-C-Mo-V steels and relationship to hydrogen trapping. Proc. R. Soc. A 2006, 462, 2315-2330. [CrossRef]

25. DNV-GL. DNVGL-CP-0237 Offshore Mooring Chain and Accessories, Class Programme; Det Norske Veritas group: Oslo, Sweden, 2018.

26. Chung, Y.; Fulton, L. Environmental hydrogen embrittlement of G4140 and G4340 steel bolting in atmospheric versus immersion services. J. Fail. Anal. 2017, 17, 330-339. [CrossRef]

27. Spanish Association of Standardization and Certification. UNE EN 10083-3:2008 Steels for Tempering and Tempering_Part 3: Technical Conditions for the Supply of Alloyed Quality Steels; AENOR: Madrid, Spain, 2008.

28. Spanish Association of Standardization and Certification. UNE-EN 10263-4 Bars, Wire Rod and Wire for Cold Deformation and Extrusion. Part 4: Technical Conditions for the Supply of Tempering and Tempering Steels; AENOR: Madrid, Spain, 2018.

29. Spanish Association for Standardization and Certification. UNE-EN ISO 898-1 Mechanical Characteristics of Carbon Steel and Alloy Steel Fasteners_Part 1: Bolts, Screws and Bolts with Specified Quality Classes; AENOR: Madrid, Spain, 2015.

30. Spanish Association of Standardization and Certification. UNE-EN ISO 6892-1:2017 Metallic Materials. Traction Tests. Part 1: Test Method at Room Temperature; AENOR: Madrid, Spain, 2017.

31. ASTM. D1141-98 Standard Practice for the Preparation of Substitute Ocean Water; American Society for Testing Materials: West Conshohocken, PA, USA, 2013.

32. ASTM. ASTM D1193-06(20018) Standard Specification for Reagent Water; Reapproved; American Society for Testing Materials: West Conshohocken, PA, USA, 2018.

33. ASTM. G129-00(2013) Standard Practice for Slow Strain Rate Testing to Evaluate the Susceptibility of Metallic Materials to Environmentally Assisted Cracking; American Society for Testing Materials: West Conshohocken, PA, USA, 2013. 
34. Álvarez, J.A.; Lacalle, R.; Arroyo, B.; Cicero, S.; Gutiérrez-Solana, F. Failure analysis of high strength galvanized bolts used in steel towers. Metals 2016, 6, 163. [CrossRef]

Publisher's Note: MDPI stays neutral with regard to jurisdictional claims in published maps and institutional affiliations.

(C) 2020 by the authors. Licensee MDPI, Basel, Switzerland. This article is an open access article distributed under the terms and conditions of the Creative Commons Attribution (CC BY) license (http://creativecommons.org/licenses/by/4.0/). 